\title{
Postoperative Nausea and Vomiting Prophylaxis with Ondansetron in Diagnostic Gynecologic Laparoscopy: Preemptive versus Preventive Method
}

\author{
Simin Atashkhoei ${ }^{1}$, Eissa Bilehjani ${ }^{1}$, Solmaz Fakhari ${ }^{*}{ }^{*}$, Faraji-Azad Hanieh ${ }^{2}$ \\ ${ }^{1}$ Department of Anesthesiology, Tabriz University of Medical Sciences, Tabriz, Iran \\ ${ }^{2}$ Tabriz University of Medical Sciences, Tabriz, Iran \\ Email: satashkhoyi@gmail.com, isadavod@gmail.com, ${ }^{\star}$ solmaz_fakhari@yahoo.com, haniehfarajit@gmail.com
}

How to cite this paper: Atashkhoei, S., Bilehjani, E., Fakhari, S. and Hanieh, F.-A. (2017) Postoperative Nausea and Vomiting Prophylaxis with Ondansetron in Diagnostic Gynecologic Laparoscopy: Preemptive versus Preventive Method. Advances in Reproductive Sciences, 5, 1-9. https://doi.org/10.4236/arsci.2017.51001

Received: December 7, 2016

Accepted: January 10, 2017

Published: January 13, 2017

Copyright $\odot 2017$ by authors and Scientific Research Publishing Inc. This work is licensed under the Creative Commons Attribution International License (CC BY 4.0).

http://creativecommons.org/licenses/by/4.0/

(c) (i) Open Access

\begin{abstract}
Background and Objective: Post-operative nausea and vomiting (PONV) is a common adverse effect of the anesthesia in laparoscopic surgery. Ondansetron has been used for prevention and treatment of the PONV. The purpose of the present study was to compare the effects of preemptive and preventive intravenous ondansetron on PONV in patients undergoing diagnostic gynecologic laparoscopy. Materials \& Methods: In a randomized double-blind clinical trial, 80 women candidate of diagnostic laparoscopy, were enrolled to study in two preemptive or preventive groups $(\mathrm{n}=40)$. Ondansetron $4 \mathrm{mg}$ IV was administered $5 \mathrm{~min}$ before anesthesia induction or $5 \mathrm{~min}$ before extubation in preemptive or preventive groups, respectively. The frequency and severity of the PONV were compared at post-anesthetic care unit (PACU), 3th, 6th and 24th postoperatively in two groups. Also the first time of need for the antiemetic drug was studied. Results: Demographic data were similar but duration of anesthesia was shorter in preventive group. The PONV rate was similar in two groups [ $37.5 \%$ and $32.5 \%$ in preemptive and preventive groups, respectively $(\mathrm{P}=0.815)]$. In preemptive group it was more intense at $\mathrm{PACU}$ and 24 hours after surgery ( $\mathrm{P}$-value $<0.05)$ and rate of vomiting was high (11 vs. 3, P-value 0.037). The first request for antiemetic drug was earlier and the antiemetic consumption dose ( $\mathrm{P}$-value $<0.05)$, recovery and hospital stay times were high in preemptive group ( $\mathrm{P}$-value $=0.001)$. Conclusion: Preventive ondansetron is more effective than preemptive form, in reducing the severity of PONV but not rate of the PONV in diagnostic gynecologic laparoscopy.
\end{abstract}

\section{Keywords}

Gynecologic Laparoscopy, PONV, Ondansetron, Preemptive, Preventive 


\section{Introduction}

Diagnostic laparoscopy is generally performed on patients with inexcusable infertility following unsuccessful treatment [1]. Post-operative nausea and vomiting (PONV) is a typical complication following surgery, especially a laparoscopic one. Nausea, vomiting, or retching within the first $24-48$ hours of surgery, is commonly referred to as PONV [2]. The incidence of PONV is approximately $20 \%-30 \%$, able to reach $70 \%$ after laparoscopic surgeries [3]. Female gender is one of the strongest predictors of PONV [4]. It has been reported that the incidence of PONV following gynecologic laparoscopic procedure is around 52\% $92 \%[5]$.

PONV entails a myriad of complications such as dissatisfaction, discomfort, acid-base disturbance, dehydration, electrolyte imbalance, high blood pressure, intraocular and/or intracranial pressures, tachycardia, late convalescence, prolonged hospital stay and the concomitant increase in costs [5] [6] [7]. Patients at risk of developing PONV have to receive prophylactic doses of antiemetic drugs [8]. One of the best methods for the prevention of PONV is to preemptively or preventively administrate prophylactic antiemetic drugs. These drugs are, more often than not, expensive and bring about certain adverse effects, hence the fact that the chosen drug must have minimal side effects and the ability to reduce nausea and vomiting [9] [10]. Ondansetron is a 5-hydroxytryptamine receptor (5-HT) antagonist with confirmed anti-nausea and anti-vomiting effects which does not result in sedation, euphoria, restlessness, dryness of mouth, tachycardia, mydriasis, and urine retention, and does not have extra pyramidal side effects [11]. The prophylactic dose of ondansetron is $4 \mathrm{mg}$, its onset time is 10 min; its pick effect is $15-30$ min following injection and its duration of action is $4-8 \mathrm{~h}$. The most common side effects reported for ondansetron are headache, diarrhea and allergic reactions [7].

The dose, time and method of administrating such antiemetic drugs as ondansetron are very important when preventing PONV. The present study was, therefore, designed to appraise and compare the effects of single-dose preemptive (pre-operative) with preventive (at the end of surgery or procedure) ondansetron on PONV in patients undergoing diagnostic gynecologic laparoscopy.

\section{Materials and Methods}

\section{Patients}

This randomized, double-blind clinical trial was approved by the Local Institute Ethics Committee of Tabriz University of Medical Sciences and registered in Iranian Registration Clinical Trial Center (www.irct.ir) as IRCT201402037013N9. Written consent forms were obtained from all enrolled patients. Our population included women who, due to infertility, referred to Al-Zahra Teaching Hospital of Tabriz for diagnostic laparoscopy under general anesthesia, from February 2014 to October 2014. In a simple sampling method and based on the previously reported prevalence of $18.2 \%$ and $44.4 \%$ for nausea and vomiting [12], $\alpha=0.05$, power $=0.8$, effect size $=0.3$ and drop up $=0.1$, a total of 80 patients were included. 
All ASA I women with aged 20 - 40 years and history of infertility, who were candidate of elective diagnostic gynecologic laparoscopy, after obtaining informed consent, were enrolled to the present study. Exclusion criteria were women apart from ASA I, lack of informed consent, patients with vaginal bleeding, recent use of steroids, narcotics and antiemetic drugs, history of cardiovascular, pulmonary, renal and endocrine diseases, history of motion sickness, gastrointestinal diseases, pregnancy and body mass index (BMI) of higher than $30 \mathrm{~kg} / \mathrm{m}^{2}$. Making use of Rand-list software, patients were randomly divided into preemptive and preventive groups, each comprised of 40 subjects.

\section{Interventions}

The preemptive group received $4 \mathrm{mg}$ ondansetron $5 \mathrm{~min}$ prior to the induction of general anesthesia. In the preventive group, the same dose was administered $5 \mathrm{~min}$ before extubation. After preoxygenation, all patients underwent intravenous anesthesia in the following sequence of injections: $0.05 \mathrm{mg} / \mathrm{kg} \mathrm{mi}$ dazolam, $2 \mu \mathrm{g} / \mathrm{kg}$ fentanyl, and $2 \mathrm{mg} / \mathrm{kg}$ propofol. The airway managed with appropriate sized laryngeal mask airway (LMA). Anesthesia was maintained through the propofol infusion of $50-150 \mu \mathrm{g} / \mathrm{kg} / \mathrm{h}$ and $0.2-0.3 \mathrm{mg} / \mathrm{kg}$ atracurium. Mechanical ventilatory support was employed so as to maintain of the end-tidal $\mathrm{CO}_{2}$ pressure $\left(\mathrm{Et}^{\mathrm{CO}_{2}}\right)$ with $35 \pm 5 \mathrm{mmHg}$. The patient monitoring was performed via pulse oximetry, non-invasive blood pressure check, electrocardiography and capnography. Abdominal insufflations with $\mathrm{CO}_{2}$ were conducted with an intraabdominal pressure less than $14 \mathrm{mmHg}$. At the end of the operation, the intraabdominal gas was released and ports of Laparoscopy were removed. Furthermore, residual neuromuscular blockage was appropriately reversed and LMA was removed.

\section{Monitoring}

Patients were monitored, in the post anesthesia care unit and also at 3, 6, and 24 hours after operation, for the presence of the nausea and/or vomiting. The intensity of the PONV was classified as: 0: without PONV, 1: nausea, 2: vomiting and 3: vomiting more than 2 times [13]. In addition, the incidence of PONV, the first time there was need for antiemetic drugs and their total dose were recorded. With PONV score $\geq 2$, we used $5 \mathrm{mg}$ metoclopramide IV for antiemetic regimen. Two surgeons were responsible for laparoscopy. Two anesthesiologists were responsible for the monitoring and anesthetic management of patients, while another, oblivious to the time of ondansetron administration (preemptive and preventive), recorded patient's information and completed the checklist. Vomiting was defined as either vomiting (expulsion of stomach contents) or retching (an involuntary attempt to vomit, yet with no expulsion of stomach contents). Nausea was defined as the unpleasant sensation associated with the awareness of the urge to vomit [14]. The side effects of ondansetron such as headache, dizziness, allergic reactions, constipation and muscular pain were further assessed.

Also recorded were the operation period from the first incision to the last suture, anesthesia time from the injection to LMA removal, recovery period from 
the operation room discharge to recovery room discharge, and hospitalization time from the end of anesthesia to discharge from hospital.

\section{Statistical analysis}

All data were processed using SPSS version 17. Quantitative variables were reported as mean \pm SD and analyzed utilizing two independent sample $t$ tests. Qualitative variables were reported as frequency (percentage) and analyzed using chi-square test. P-value $<0.05$ was considered as a significant difference.

\section{Results}

All patients completed the study. Demographic data and duration of the surgery were similar in two groups but the duration of anesthesia was shorter in preventive group (Table 1).

Table 2 illustrates the frequency and intensity of PONV at the times of recovery and hospital stay. The Results shows that comparing to preemptive method, the preventive ondansetron reduced PONV only by $5 \%$ and indeed the PONV rate was similar in two groups [(37.5\% and $32.5 \%$ in preemptive and preventive groups, respectively $(\mathrm{P}=0.815)]$. However $\mathrm{PONV}$ generally was more intense in the preemptive group at the PACU and 24 hours after surgery $(\mathrm{P}$-value $<0.05)$ and rate of vomiting was high in preemptive group (11 vs. 3 episodes, $\mathrm{P}$-value $=$ 0.037). The total consumed antiemetic dose as metoclopramide was 100 and 75 $\mathrm{mg}$ in preemptive and preventive groups, respectively. The first request for antiemetic drug was earlier in preemptive group $(6.42 \pm 2.69$ vs. $8.01 \pm 3.14 \mathrm{hrs}$, $\mathrm{P}$-value $<0.05)$ and the antiemetic consumption dose as $\mathrm{mg} /$ person was high in preemptive group $(2.5 \pm 0.32$ vs. $1.75 \pm 2.6 \mathrm{mg}$, $\mathrm{P}$-value $<0.05)$. Both recovery and hospital stay times were high in preemptive group $(\mathrm{P}$-value $=0.01)$. No adverse effect was seen in the any patient (Table 2).

There was No any difference between different age groups in the preemptive or preventive groups.

Figure 1 shows the trend of the PONV intensity in the preemptive and preventive groups. The PONV was more intense in the preemptive group at the PACU and 24 hours after surgery.

Table 1. The illustration of the demographic data, duration of the anesthesia and surgery in two groups.

\begin{tabular}{cccc}
\hline & \multicolumn{3}{c}{ Groups } \\
\cline { 2 - 3 } & Preemptive $(\mathrm{N}=40)$ & Preventive $(\mathrm{N}=40)$ & P-value \\
\hline Age (years) & $31.63 \pm 1.9$ & $32.7 \pm 2.9$ & 0.054 \\
Weight $(\mathrm{kg})$ & $66.9 \pm 6.23$ & $65.6 \pm 5.41$ & 0.332 \\
Height $(\mathrm{cm})$ & $162.5 \pm 5.73$ & $161.0 \pm 6.48$ & 0.276 \\
Mean arterial blood pressure $(\mathrm{mmHg})$ & $92.11 \pm 8.6$ & $89.78 \pm 9.2$ & 0.2455 \\
Hemoglobin (g/dl) & $13.13 \pm 1.14$ & $12.94 \pm 1.21$ & 0.472 \\
Duration of surgery (min) & $50.03 \pm 4.9$ & $48.13 \pm 5.19$ & 0.093 \\
Duration of anesthesia (min) & $61.33 \pm 3.08$ & $59.23 \pm 5.1$ & $0.029^{*}$ \\
\hline
\end{tabular}

Data represented as mean \pm SD. ${ }^{\star S i g n i f i c a n t ~ d i f f e r e n c e s ~ b e t w e e n ~ t w o ~ g r o u p s . ~}$ 
Table 2. The illustration of the PONV characteristic in the preemptive and preventive groups.

\begin{tabular}{|c|c|c|c|}
\hline & \multicolumn{2}{|c|}{ Group } & \multirow[b]{2}{*}{$\begin{array}{c}\mathrm{P} \\
\text { value }\end{array}$} \\
\hline & $\begin{array}{l}\text { Preemptive } \\
(\mathrm{N}=40)\end{array}$ & $\begin{array}{c}\text { Preventive } \\
(\mathrm{N}=40)\end{array}$ & \\
\hline \multicolumn{4}{|l|}{ PONV incidence, frequency (\%) } \\
\hline Recovery & $8(20)$ & $6(15)$ & 0.769 \\
\hline 3 hours & $5(12.5)$ & $6(15)$ & 1.0 \\
\hline 6 hours & $5(12.5)$ & $5(12.5)$ & 1.0 \\
\hline 24 hours & $2(5)$ & $1(2.5)$ & 1.0 \\
\hline Total & $15(37.5)$ & $13(32.5)$ & 0.815 \\
\hline \multicolumn{4}{|l|}{ PONV score mean (SD) } \\
\hline Recovery & $0.28 \pm 0.09$ & $0.18 \pm 0.07$ & $0.001^{\rtimes}$ \\
\hline 3 hours & $0.23 \pm 0.08$ & $0.2 \pm 0.08$ & 0.975 \\
\hline 6 hours & $0.18 \pm 0.07$ & $0.2 \pm 0.08$ & 0.238 \\
\hline 24 hours & $0.1 \pm 0.07$ & $0.06 \pm 0.05$ & $0.043^{\star}$ \\
\hline Total & $0.75 \pm 0.18$ & $0.63 \pm 0.16$ & $0.023^{\star}$ \\
\hline Frequency of $\mathrm{PONV} \geq 2$ & $11(27.5)$ & $3(7.5)$ & $0.037^{\star}$ \\
\hline The time of the first antiemetic request (hour) & $6.42 \pm 2.69$ & $8.01 \pm 3.14$ & $0.017^{\times}$ \\
\hline Total antiemetic consumption (metoclopramide) (mg) & 100 & 70 & --- \\
\hline Antiemetic consumption $\mathrm{mg} /$ person & $2.5 \pm 0.32$ & $1.75 \pm 2.6$ & $0.001^{\times}$ \\
\hline Recovery time (min) & $25.93 \pm 1.90$ & $23.75 \pm 1.45$ & $0.001^{\times}$ \\
\hline Hospital stay (h) & $24.11 \pm 0.40$ & $22.48 \pm 0.41$ & $0.001^{\times}$ \\
\hline
\end{tabular}

PONV: post-operative nausea and vomiting. ${ }^{\star}$ Significant differences between two groups.

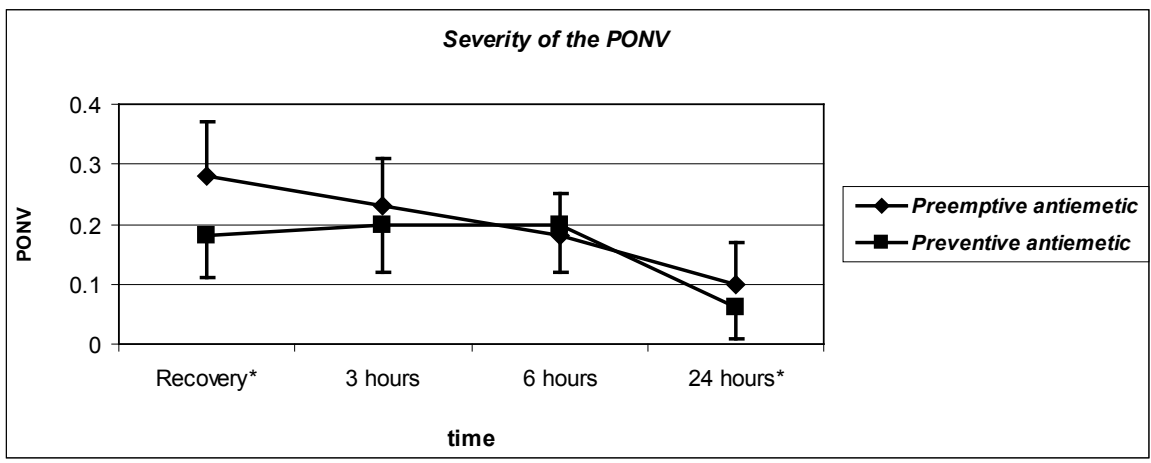

Figure 1. The trend of the PONV intensity in the preemptive and preventive groups. (PONV: post-operative nausea and vomiting. ${ }^{*}$ Significant differences between two groups).

\section{Discussion}

PONV is one of the most unpleasant experiences and among the most common reasons for patients' dissatisfaction post operation, hence the significance of prophylactic strategy. In the present study, we focused on the beneficial effects of IV ondansetron on the prevention of PONV after diagnostic gynecologic laparoscopy. Various studies have shown the positive effects of ondansetron on PONV. However, there exist few studies as to the most propitious time the on- 
dansetron should be prescribed. We found that preventive administration of ondansetron entails a better outcome compared with its preemptive injection.

Panda et al. reported that administration of $4 \mathrm{mg}$ ondansetron 30 minutes prior the end of surgery lowered nausea and vomiting by $28 \%$ in 100 patients after general anesthesia [15]. In another study, Isik and colleagues compared the antiemetic effects of $1 \mathrm{~g}$ dexamethasone and $4 \mathrm{mg}$ ondansetron on 60 patients 24 $\mathrm{h}$ after operation, where it was found that the rate of nausea and vomiting and the amount of drug used in ondansetron group were significantly lower than the dexamethasone group. The cost of administering ondansetron, on the other hand, was higher in comparison to dexamethasone [16]. Wang et al. evaluated the results of different studies, with a total of 608 patients, in a systematic review to compare the effects of dexamethasone and ondansetron as regards preventing PONV in patients undergoing laparoscopic surgery. They reported that dexamethasone was as effective and safe as ondansetron in preventing PONV [17].

Hartsell et al. studied the antiemetic effects of ondansetron in patients with craniotomy where they found that administering ondansetron, rather than placebo, prior to extubation could decrease the need for antiemetics [18]. In line with the fore going studies, the present research indicated that employing ondansetron preventively decreases the required dose (70 vs. $100 \mathrm{mg})$ and increases the first request time (from $6.42 \pm 2.69$ to $8.01 \pm 3.14 \mathrm{hrs}$ ) of antiemetic drugs in comparison with preemptive approaches. In addition, we found that the total rate of PONV after injecting ondansetron was $32.5 \%$ or $37.5 \%$, which is close to the rate found in Wang et al., with the data of seven previous studies [13] [17] [19]-[24].

Sarkar et al. reported that the use of ondansetron in a preemptive route exerted higher effects on PONV after laparoscopic surgery and, during the first 24 hrs, decreased the vomiting rate more than metoclopramide [25]. In a recent study, Bataile and colleagues found that PONV, during the first 24 hours, occurred in $45 \%$ of patients who received $4 \mathrm{mg}$ intravenous dexamethasone after tracheal intubation and $4 \mathrm{mg}$ ondansetron during skin closure, which was lower than the placebo group. Nevertheless, the number of patients who suffered from severe PONV and required rescue antiemetic drugs was similar in both groups. They concluded that combining dexamethasone and ondansetron was not effective in precluding (severe) PONV [26]. In accordance with all the previous reports, except for Bataile et al., we found that administering ondansetron reduced the incidence of PONV score $\geq 2$ throughout the first $24 \mathrm{hr}$ postoperatively. In our study, the reduction in nausea, vomiting and PONV scores in the first hour after the operation was more than the following hours, the most effective time being recovery period in PACU. Administration before extubation significantly reduced the recovery period and hospital stay. In the present research, the anesthesia time was shorter in the preventive group than in the preemptive group. Assuming that the surgery time is more than an hour to be listed as a risk factor for PONV, it seems that the difference in that time did not affect the final results. 
The ondansetron showed no adverse effects in either methods of administration. Despite the beneficial effects of dexamethasone on PONV, it has been reported that an intravenous bolus dose of dexamethasone could induce vaginal itching and anal inflammation [27] Other antiemetic drugs such as antihistamines, metoclopramide, and droperidol bring certain side effects such as hypotension, xerostomia, dysphoria, hallucination and extra pyramidal symptoms [11] [13].

Accordingly, the results suggest that ondansetron administration before extubation has better clinical outcomes than before anesthesia, a fact that can be associated with the pharmacokinetic and pharmacodynamic characteristics of the drug. Owing to the rapid $(10 \mathrm{~min})$ onset of intravenous ondansetron, and the peak effect time which is around 15 - 30 minutes after injection, the findings of our study can justify the reduction in the incidence of PONV in PACU and the reduction of severe cases, the reduced recovery and subsequent decrease in the dose of antiemetic request and hospital stay.

\section{Conclusion}

In conclusion, the preventive IV ondansetron is more effective than preemptive ondansetron in reducing the severity of PONV in diagnostic gynecologic laparoscopy; however the rate of the PONV may not be affected. This method of administration may also decrease the antiemetic consumption dose as $\mathrm{mg} /$ person. This preventive method may also shorten the recovery and hospital stay periods.

\section{References}

[1] Tsuji, I., Ami, K., Miyazaki, A., Hujinami, N. and Hoshiai, H. (2009) Benefit of Diagnostic Laparoscopy for Patients with Unexplained Infertility and Normal Hysterosalpingography Findings. The Tohoku Journal of Experimental Medicine, 219, 39 42. https://doi.org/10.1620/tjem.219.39

[2] Choi, S.U. (2016) Is Postoperative Nausea and Vomiting Still the Big. Korean Journal of Anesthesiology, 69, 1-2. https://doi.org/10.4097/kjae.2016.69.1.1

[3] Maitra, S., Som, A., Baidya, D.K. and Bhattacharjee, S. (2016) Comparison of Ondansetron and Dexamethasone for Prophylaxis of Postoperative Nausea and Vomiting in Patients Undergoing Laparoscopic Surgeries: A Meta-Analysis of Randomized Controlled Trials. Anesthesiology Research and Practice, 2016, Article ID: 7089454.

[4] Apfel, C., Heidrich, F., Jukar-Rao, S., Jalota, L., Hornuss, C., Whelan, R., et al. (2012) Evidence-Based Analysis of Risk Factors for Postoperative Nausea and Vomiting. British Journal of Anaesthesia, 109, 742-753. https://doi.org/10.1093/bja/aes276

[5] Chauhan, G., Madan, D., Gupta, K., Kashyap, C., Maan, P. and Nayar, P. (2013) Effect of Intraoperative Intravenous Crystalloid Infusion on Post-Operative Nausea and Vomiting after Diagnostic Gynaecological Laparoscopy: Comparison of $30 \mathrm{ml} / \mathrm{kg}$ and $10 \mathrm{ml} / \mathrm{kg}$ and to Report the Effect of the Menstrual Cycle on the Incidence of Post-Operative Nausea and Vomiting. Anesthesia, Essays and Researches, 7, 100. https://doi.org/10.4103/0259-1162.114013

[6] Antor, M.A., Uribe, A.A., Erminy-Falcon, N., Werner, J.G., Candiotti, K.A., Pergolizzi, J.V., et al. (2014) The Effect of Transdermal Scopolamine for the Prevention of Postoperative Nausea and Vomiting. Frontiers in Pharmacology, 5, 55. 
https://doi.org/10.3389/fphar.2014.00055

[7] McCracken, G., Houston, P. and Lefebvre, G. (2008) Guideline for the Management of Postoperative Nausea and Vomiting. Journal of Obstetrics and Gynaecology Canada, 30, 600-607. https://doi.org/10.1016/S1701-2163(16)32895-X

[8] Pierre, S. and Whelan, R. (2013) Nausea and Vomiting after Surgery. Continuing Education in Anaesthesia, Critical Care \& Pain, 13, 28-32. https://doi.org/10.1093/bjaceaccp/mks046

[9] Hill, R.P., Lubarsky, D.A., Phillips-Bute, B., Fortney, J.T., Creed, M.R., Glass, P.S., et al. (2000) Cost-Effectiveness of Prophylactic Antiemetic Therapy with Ondansetron, Droperidol, or Placebo. The Journal of the American Society of Anesthesiologists, 92, 958-967. https://doi.org/10.1097/00000542-200004000-00012

[10] Watcha, M.F. and Smith, I. (1994) Cost-Effectiveness Analysis of Antiemetic Therapy for Ambulatory Surgery. Journal of Clinical Anesthesia, 6, 370-377. https://doi.org/10.1016/S0952-8180(05)80006-6

[11] Islam, S. and Jain, P.N. (2004) Post-Operative Nausea and Vomiting (PONV): A Review Article. Indian Journal of Anaesthesia, 48, 253-258.

[12] Grover, V., Mathew, P. and Hegde, H. (2009) Efficacy of Orally Disintegrating Ondansetron in Preventing Postoperative Nausea and Vomiting after Laparoscopic Cholecystectomy: A Randomised, Double-Blind Placebo Controlled Study. Anaesthesia, 64, 595-600. https://doi.org/10.1111/j.1365-2044.2008.05860.x

[13] D’souza, N., Swami, M. and Bhagwat, S. (2011) Comparative Study of Dexamethasone and Ondansetron for Prophylaxis of Postoperative Nausea and Vomiting in Laparoscopic Gynecologic Surgery. International Journal of Gynecology \& Obstetrics, 113, 124-127. https://doi.org/10.1016/j.ijgo.2010.11.022

[14] Zhang, D., Shen, Z., You, J., Zhu, X. and Tang, Q.-F. (2013) Effect of Ondansetron in Preventing Postoperative Nausea and Vomiting under Different Conditions of General Anesthesia: A Preliminary, Randomized, Controlled Study. Upsala Journal of Medical Sciences, 118, 87-90. https://doi.org/10.3109/03009734.2013.768315

[15] Panda, N.B., Bharadwaj, N., Kapoor, P., Chari, P. and Panda, N.K. (2004) Prevention of Nausea and Vomiting after Middle Ear Surgery: Combination of Ondansetron and Dexamethasone Is the Right Choice. Journal of Otolaryngology, 33, 88-92.

[16] Isik, B., Cekmen, N., Arslan, M., Ozsoylar, O., Kordan, A.Z. and Akcabay, M. (2006) Comparison of the Antiemetic Effects of Ondansetron and Dexamethasone on Middle Ear Surgery. Saudi Medical Journal, 27, 646-651.

[17] Wang, X.-X., Zhou, Q., Pan, D.-B., Deng, H.-W., Zhou, A.-G., Huang, F.-R., et al. (2015) Dexamethasone versus Ondansetron in the Prevention of Postoperative Nausea and Vomiting in Patients Undergoing Laparoscopic Surgery: A Meta-Analysis of Randomized Controlled Trials. BMC Anesthesiology, 15, 118.

https://doi.org/10.1186/s12871-015-0100-2

[18] Hartsell, T., Long, D. and Kirsch, J.R. (2005) The Efficacy of Postoperative Ondansetron (Zofran) Orally Disintegrating Tablets for Preventing Nausea and Vomiting after Acoustic Neuroma Surgery. Anesthesia \& Analgesia, 101, 1492-1496. https://doi.org/10.1213/01.ANE.0000181007.01219.38

[19] Alghanem, S.M., Massad, I.M., Rashed, E.M., Abu-Ali, H.M. and Daradkeh, S.S. (2010) Optimization of Anesthesia Antiemetic Measures versus Combination Therapy Using Dexamethasone or Ondansetron for the Prevention of Postoperative Nausea and Vomiting. Surgical Endoscopy, 24, 353-358. https://doi.org/10.1007/s00464-009-0567-3

[20] Dabbous, A.S., Jabbour-Khoury, S.I., Nasr, V.G., Moussa, A.A., Zbeidy, R.A., Khouzam, N.E., et al. (2010) Dexamethasone with Either Granisetron or Ondansetron for 
Postoperative Nausea and Vomiting in Laparoscopic Surgery. Middle East Journal of Anesthesiology, 20, 565-570.

[21] Erhan, Y., Erhan, E., Aydede, H., Yumus, O. and Yentur, A. (2008) Ondansetron, Granisetron, and Dexamethasone Compared for the Prevention of Postoperative Nausea and Vomiting in Patients Undergoing Laparoscopic Cholecystectomy. Surgical Endoscopy, 22, 1487-1492. https://doi.org/10.1007/s00464-007-9656-3

[22] Gautam, B., Shrestha, B., Lama, P. and Rai, S. (2008) Antiemetic Prophylaxis against Postoperative Nausea and Vomiting with Ondansetron-Dexamethasone Combination Compared to Ondansetron or Dexamethasone Alone for Patients Undergoing Laparoscopic Cholecystectomy. Kathmandu University Medical Journal, 6, 319-328.

[23] Kumar, A., Patodia, M., Pandove, P. and Sharda, V. (2013) A Randomized, Placebo Controlled Study Evaluating Preventive Role of Ondansetron, Dexamethasone and Ondansetron plus Dexamethasone for Postoperative Nausea and Vomiting (PONV) in Patients Undergoing Laparoscopic Cholecystectomy. JIMSA, 26, 217-218.

[24] Yuksek, M., Alici, H., Erdem, A. and Cesur, M. (2003) Comparison of Prophylactic Anti-Emetic Effects of Ondansetron and Dexamethasone in Women Undergoing Day-Case Gynaecological Laparoscopic Surgery. Journal of International Medical Research, 31, 481-488. https://doi.org/10.1177/147323000303100603

[25] Sarkar, M., Sarkar, A., Dewoolkar, L. and Charan, S. (2007) Comparative Study of Single Dose Intravenous Ondansetron and Metoclopramide as Premedication for Prevention of Postoperative Nausea and Vomiting in Obstetrical Laparoscopic Surgery under General Anesthesia. The Internet Journal of Anaesthesiology, 13, 1-5.

[26] Bataille, A., Letourneulx, J.-F., Charmeau, A., Lemedioni, P., Léger, P., Chazot, T., et al. (2016) Impact of a Prophylactic Combination of Dexamethasone-Ondansetron on Postoperative Nausea and Vomiting in Obese Adult Patients Undergoing Laparoscopic Sleeve Gastrectomy during Closed-Loop Propofol-Remifentanil Anaesthesia: A Randomised Double-Blind Placebo-Controlled Study. European Journal of Anaesthesiology, 33, 898-905. https://doi.org/10.1097/EJA.0000000000000427

[27] McKenzie, R., Kovac, A., O’Connor, T., Duncalf, D., Angel, J., Gratz, I., et al. (1993) Comparison of Ondansetron versus Placebo to Prevent Postoperative Nausea and Vomiting in Women Undergoing Ambulatory Gynecologic Surgery. Anesthesiology, 78, 21-28. https://doi.org/10.1097/00000542-199301000-00005

Scientific Research Publishing

\section{Submit or recommend next manuscript to SCIRP and we will provide best service for you:}

Accepting pre-submission inquiries through Email, Facebook, LinkedIn, Twitter, etc. A wide selection of journals (inclusive of 9 subjects, more than 200 journals)

Providing 24-hour high-quality service

User-friendly online submission system

Fair and swift peer-review system

Efficient typesetting and proofreading procedure

Display of the result of downloads and visits, as well as the number of cited articles

Maximum dissemination of your research work

Submit your manuscript at: http://papersubmission.scirp.org/

Or contact arsci@scirp.org 